\title{
Honoré de Balzac, Il Capolavoro sconosciuto
}

\section{Marco Stupazzoni}

\section{(2) OpenEdition}

\section{Journals}

\section{Edizione digitale}

URL: http://journals.openedition.org/studifrancesi/2196

DOI: 10.4000/studifrancesi.2196

ISSN: 2421-5856

\section{Editore}

Rosenberg \& Sellier

\section{Edizione cartacea}

Data di pubblicazione: 1 avril 2014

Paginazione: 160-161

ISSN: 0039-2944

\section{Notizia bibliografica digitale}

Marco Stupazzoni, « Honoré de Balzac, /l Capolavoro sconosciuto », Studi Francesi [Online], 172 (LVIII |

I) | 2014, online dal 01 avril 2014, consultato il 21 décembre 2020. URL : http://

journals.openedition.org/studifrancesi/2196; DOI : https://doi.org/10.4000/studifrancesi.2196

Questo documento è stato generato automaticamente il 21 décembre 2020.

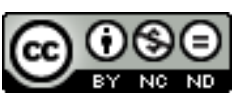

Studi Francesi è distribuita con Licenza Creative Commons Attribuzione - Non commerciale - Non opere derivate 4.0 Internazionale. 


\title{
Honoré de Balzac, Il Capolavoro sconosciuto
}

\author{
Marco Stupazzoni
}

\section{NOTIZIA}

HONORÉ DE BALZAC, Il Capolavoro sconosciuto, acqueforti e incisioni su legno di Pablo PICASSO con il testo originale in lingua francese e con un saggio di Brunella PELIZZA, a cura di Luigi BONANATE, Torino, Nino Aragno Editore, 2012 («Biblioteca Aragno»), pp. xLV-191.

1 Tra le maggiori e più note edizioni di pregio (e non soltanto pecuniario) relative ai romanzi della Comédie humaine, si annovera senza alcun dubbio quella che riguarda Le Chef-d'œuvre inconnu, pubblicata nel 1931 da Ambroise Vollard e corredata da tavole di Picasso: 12 acqueforti originali; 16 pagine di disegni, più altri 4 disegni e 67 incisioni su legno.

2 Questa eccellente nuova edizione italiana del racconto filosofico di Balzac riproduce sostanzialmente l'edizione Vollard conservandone rigorosamente l'affascinante impaginazione, alquanto suggestiva per il lettore che intenda scoprire il dialogo casuale, quasi involontario, ma certamente magico tra Balzac e Picasso.

3 L'origine delle illustrazioni per il Chef-d'œuvre inconnu è da ricondursi al periodo di sperimentazione stilistica dell'artista. Come osserva Brunella Pelizza nella sua Postfazione (Pablo Picasso, la molteplicità del segno, pp. 167-191), «Picasso non ha voluto illustrare in maniera descrittiva il contenuto dell'opera di Balzac» (p. 173): soltanto nella tavola IV delle dodici acqueforti che compongono il secondo gruppo di incisioni, e che hanno come tema Il pittore e la modella, è possibile individuare l'unica testimonianza in qualche modo «direttamente riconducibile al libro di Balzac» (p. 175).

4 È proprio sul tema dell'impossibilità di realizzare il quadro perfetto, ovvero di compiere il processo dell'atto creativo senza eccessi e senza traumi che riflette Luigi Bonanate nella sua eccellente Prefazione al testo balzachiano (pp. VII-XLIV). Se le illustrazioni di Picasso non commentano il Chef-d'œuvre inconnu, la scoperta della 
tematica del legame tra creatore e creatura, ossia tra artista (pittore) e modella rappresenta non soltanto uno dei soggetti prevalenti della pittura di Picasso a partire dal 1914, ma corrisponde ad una delle tracce fondamentali che si pone Frenhofer nel testo balzachiano.

5 In che cosa dunque si incontrano Balzac e Picasso? si chiede il Bonanate: essenzialmente «nel nesso pittore/modello» (p. xLI), nel modo in cui «il pittore si pone di fronte alla realtà» (p. XL), nella «rivoluzionaria e provocatoria opera di smantellamento della visione unilaterale, tradizionale e frontale del pittore che guarda il modello e lo riproduce» (p. XLIII). 